\title{
Melanoma in patients with Li-Fraumeni syndrome (Review)
}

\author{
FLORICA SANDRU $^{1,2}$, MIHAI CRISTIAN DUMITRASCU ${ }^{3,4}$, AIDA PETCA $^{3,5}$, \\ MARA CARSOTE $^{6,7}$, RAZVAN-COSMIN PETCA $^{8,9}$ and ADINA GHEMIGIAN ${ }^{6,7}$ \\ ${ }^{1}$ Department of Dermatology, 'Carol Davila' University of Medicine and Pharmacy, 050474 Bucharest; \\ ${ }^{2}$ Department of Dermatology, 'Elias' Emergency Hospital, 011461 Bucharest; \\ ${ }^{3}$ Department of Obstetrics and Gynecology, 'Carol Davila' University of Medicine and Pharmacy, 050474 Bucharest; \\ ${ }^{4}$ Department of Obstetrics and Gynecology, University Emergency Hospital, 050098 Bucharest; \\ ${ }^{5}$ Department of Obstetrics and Gynecology, 'Elias' Emergency Hospital, 022461 Bucharest; \\ ${ }^{6}$ Department of Endocrinology, 'Carol Davila' University of Medicine and Pharmacy, 050474 Bucharest; \\ ${ }^{7}$ Department of Endocrinology, 'C. I. Parhon' National Institute of Endocrinology, 011863 Bucharest; \\ ${ }^{8}$ Department of Urology, 'Carol Davila' University of Medicine and Pharmacy, 050474 Bucharest; \\ ${ }^{9}$ Department of Urology, 'Prof. Dr. Theodor Burghele' Clinical Hospital, 061344 Bucharest, Romania
}

Received July 20, 2021; Accepted August 20, 2021

DOI: $10.3892 / \mathrm{etm} .2021 .10998$

\begin{abstract}
Li-Fraumeni syndrome (LFS) is a cancer-prone, autosomal dominant syndrome caused by underlying germline gene mutations of TP53, a tumor-suppressor gene encoding the p53 protein with a major role in apoptosis, DNA repair and cell cycle regulation. Cumulative cancer incidence for LFS patients by the age of 70 years is $80-100 \%$, mostly involving adrenocortical carcinoma, brain tumors, bone and soft tissue sarcomas, leukemia and female breast cancer from the age of 20 years. Dominant negative TP53 variant is correlated with an increased tumorigenesis risk in LFS. Sporadic TP53 mutations are related to almost half of global cancers since p53 in addition to 773 protein represent essential players in anticancer cellular protection. Epidemiological aspects concerning skin cancers, especially malignant melanoma (MM), in LFS are less clear. A low level of statistical evidence demonstrates LFS cases with pediatric MM, multiple MM, spitzoid MM, atypical presentations, mucosal and uveal MM. Retrospective cohorts indicate a higher cumulative risk than the general population by the age of 70 years for MM and basal cell carcinoma. Non-syndromic and syndromic TP53 mutations are a major pathway of metastasis, including MM. In LHS, an important level of awareness involves skin cancers despite not being a part of the typical malignancy-containing picture. Additional data are crucially
\end{abstract}

Correspondence to: Dr Mihai Cristian Dumitrascu, Department of Obstetrics and Gynecology, 'Carol Davila' University of Medicine and Pharmacy, 169 Splaiul Independenţei, District 5, 050474 Bucharest, Romania

E-mail: drdumitrascu@yahoo.com

Key words: melanoma, skin cancer, Li-Fraumeni syndrome, TP53 gene, p53 protein, adrenocortical carcinoma, breast cancer, osteosarcoma, radiotherapy needed. However, at least one dermatologic control is a step in the multidisciplinary panel of surveillance of these patients; but in cases with benign and pre-malign pigmentations, serial dermatoscopy and full body photography are recommended for early melanoma detection in order to improve the prognosis and to reduce the overall malignancy burden.

\section{Contents}

1. Introduction

2. Aim of the review

3. Genetic background: TP53 mutations

4. Tumorigenesis in Li-Fraumeni syndrome

5. Melanoma in patients with Li-Fraumeni syndrome

6. Future considerations

7. Conclusions

\section{Introduction}

Li-Fraumeni syndrome (LFS) is a cancer prone, autosomal dominant, hereditary syndrome (1). Patient with LFS have a very early onset of underlying neoplasia during life; $10-15 \%$ of all malignancies in the pediatric population are found associated with LFS in addition to more than 100 gene anomalies, including the TP53 gene $(1,2)$. Starting from childhood, early diagnosis of brain cancer, leukemia in addition to sarcomas of the skeleton and soft tissue, and adrenocortical cancer have been reported (3). In young females, there is a higher risk of mammary cancer (1). This particular aspect needs to be differentiated from other gynecological cancers with a hereditary pattern such as Peutz-Jeghers syndrome, Lynch syndrome, BRCA1- and BRCA2-associated disease, and Cowden syndrome (4).

Specific protocols of screening, management and lifelong surveillance for LFS patients have been developed (5). A large study on 286 subjects carrying a TP53 mutation (from 
107 families) showed a cumulative cancer incidence of $100 \%$ (by the age of 70 years), and $50 \%$ by the age of 46 (males) and 31 years (females). Women have the most increased incidence of malignancy after the age of 20 years (because of mammary cancer, with a cumulative incidence of $54 \%$ by the age of 70 ) while men exhibit a high incidence early during childhood and later during adulthood. The cumulative incidence (by the age of 70 years) for females and males was found to be 15 and $22 \%$ respectively for soft tissue sarcoma, 5 and $11 \%$ respectively for osteosarcoma, 6 and 19\% respectively for central nervous system tumors; with a second tumor diagnosed after a median of a decade in almost half of patients (6).

\section{Aim of the review}

The present review was designed with an aim to introduce a practical overview of published data regarding LFS and associated malignancies focusing on melanoma. This is a brief narrative review of literature underling a PubMed research on LFS and associated malignancies, especially malignant melanoma (MM). Most of the published papers involving specific data on LFS and melanoma were found to be of a low level of evidence, mainly case reports or cases series, but also we found two retrospective studies. The perspective of approach was clinical and multidisciplinary. The inclusion criteria of the citations were full-length English papers that were recently published with the majority of the 61 articles published within the last three years. Due to the rarity of the topic, a heterogeneous level of statistical evidence was used in order to offer a real-life medical picture of the selected topic.

\section{Genetic background: TP53 mutations}

LFS is related to germline mutations of the TP53 gene (chromosome 17) with high penetrance. TP53 is a tumor-suppressor gene that encodes the p53 protein with a major role in apoptosis, DNA repair and cell cycle regulation (7). While germline mutations cause LFS, sporadic mutations are related to almost half of global cancers (mostly non-syndromic presentation), because the $\mathrm{p} 53$ protein in addition to $\mathrm{p} 73$ protein represent essential players in human body anticancer protection at the cellular level (8). The p53 protein is responsible for cell cycle function in order either to maintain adequate homeostasis or to induce cell cycle arrest thus causing cell death (9).

The mutation profile is a prognostic factor in associated malignancies; tumor heterogeneity being related to incomplete protein inactivation (7). Hotspot variant and truncating variants are correlated with a higher incidence of cancer and an earlier age at presentation (10). Dominant negative variant is generally recognized with an overall higher cancer risk (1). TP53 $(\mathrm{R} 337 \mathrm{H})$ mutation is particularly prevalent in Brazil where population clusters of pediatric adrenocortical carcinomas or sarcomas have been described (11). Not all TP53 carriers develop tumors through their entire lifespan, but those who do, are associated with a clinical picture of an $80-100 \%$ penetrance by the age of 70 years (12). Some aspects of the genotype-phenotype correlations are well known until present but there are still open issues (12). The timing of tumors in LFS includes the following: between birth and 15 years, adrenocortical carcinoma in association with choroid plexus carcinoma are prominent; between 16 and 50 years, breast cancers in females, sarcomas, astrocytoma, and leukemia are prominent; between 51 and 80 years, pancreatic carcinoma in both sexes and prostate cancer in males are prominent (12).

\section{Tumorigenesis in Li-Fraumeni syndrome}

We mention the importance of a general picture in LFS, which represents a standard multidisciplinary approach, both in terms of diagnosis and therapy (1). Yearly magnetic resonance imaging (MRI) is recommended for tumor screening (13). Whole-body sequences are mostly useful and, since the technique is not radiant, it is feasible in the pediatric population (14). In subjects with positive TP53 mutations, the protocol of imaging follow-up during childhood includes: annual whole body and brain MRI from the first year of life (and bi-annual abdominal ultrasound). In adults, yearly brain MRI should be implemented until the age of 50 years in addition to annual whole body MRI. For women, this should include annual mammary MRI until the age of 65-70 years (1).

LFS-related cancers, especially pediatric cancers are highly sensitive to radiotherapy (15). On the other hand, an alarming risk of radiation-induced second malignancy has been reported in carriers of TP53 germline mutations, as well as a higher risk in tumorigenesis caused by conventional genotoxic chemotherapy (16). For instance, the prevalence of secondary sarcoma is higher than that noted in the general population (15). It is essential to identify the TP53 status in patients with different malignancies who otherwise would be candidates for radiotherapy and genotoxic chemotherapy, because these therapeutic procedures should be avoided, if possible (1).

As mentioned, the large area of LFS-related tumorigenesis is extended as following. Osteosarcoma, the most frequent primary malignancy of the skeleton in children and teenagers and the third most frequent in adults, involves TP53 mutations in the majority of cases (17). $R B 1$ mutations (retinoblastoma syndrome) are described in almost one-fifth of osteosarcoma cases, while other rarer syndromic circumstances involve Werner syndrome or Bloom syndrome (18).

Hereditary syndrome-related primary genitourinary rhabdomyosarcoma needs to be differentiated from DICERI mutations, Noonan syndrome, Costello syndrome, neurofibromatosis type 1, and Beckwith-Wiedemann syndrome $(19,20)$.

Since TP53 mutations represent an important cause of breast cancer before the age of 31 years, for cases with a positive TP53 mutation, annual screening should be performed as well as in TP53-positive patients who are survivors of mammary cancer (21). Overall, half of female patients with TP53 germline mutations present with breast cancer by the age of 70 years (22). On the other hand, in females presenting with a mammary malignancy at an early age and unknown genetic background, TP53 analysis should be assessed, especially if testing for $B R C A 1$ and $B R C A 2$ mutations is negative (23). A TP53 carrier, regardless of the full manifestation of LFS, has a 3 times higher risk of breast cancer when compared to the global population (except for BRCA1 and $B R C A 2$ carriers) (24). Radiotherapy may be useful in breast cancer related to LFS or Li-Fraumeni-like syndrome, but the rate of radiotherapy-related malignancy represents a massive concern (25). 
LFS is associated with a higher risk of tumors located in the central nervous system (such as astrocytoma, glioblastoma and choroid plexus carcinoma) and close surveillance is necessary (26). Loss of TP53 function and gain of function in mutant variants are both connected with brain cancers (27).

Hematological malignancies associated with LFS have also reported. These include leukemia of lymphoid type (acute lymphoblastic leukemia) and of myeloid type (acute myeloid or chronic myeloid leukemia), and myelodysplastic syndrome and less often lymphoma (28). The potential of inducing these disorders may be related to the actual therapy which is applied for some concurrent solid cancers (such as radiotherapy or certain types of chemotherapy) (29).

LFS has a dramatic impact on adrenocortical carcinoma incidence; $50-80 \%$ of subjects diagnosed with LFS during infancy have syndromic TP53 mutation, while $10 \%$ of adult cases have a genetic anomaly, either LFS or Lynch syndrome (30). A high index of suspicion is necessary in cases of children diagnosed with adrenal cancer and unknown family medical history; TP53 analysis is indicated under these circumstances $(31,32)$.

\section{Melanoma in patients with Li-Fraumeni syndrome}

Patients with LFS have an increased lifetime cumulative rate of different familial cancers as mentioned before; yet the exact epidemiological data concerning skin cancers, especially MM, are limited (33). Generally, it is considered that melanoma is diagnosed less frequently in TP53 carriers when compared to the previously mentioned neoplasias, but more frequent when compare to the general population $(33,34)$. Melanoma in the pediatric population with LFS has also been reported (34). Exceptional cases with multiple melanoma have been found, as well $(35,36)$. In addition, pediatric Spitzoid melanoma which is not typically involved in syndromic associations, was reported in a young patient with TP53 mutation, also associated with choroid plexus carcinoma and myelodysplasic syndrome (37).

Atypical forms of melanoma have been reported with a very low level of evidence (38). A first case of mucosal melanoma was reported in a female of 21 years as a first presentation of LFS; hematologic malignancies were subsequently identified among other family members caring the TP53 mutation (39). Uveal MM has been described in a few cases (40). An analysis of LFS and POT1 gene anomalies was assessed and incidental diagnosis of melanoma was pointed out (41). A cases series on two 28-year-old twins with LFS found familial melanoma, suggesting that follow-up of moles based on dermoscopy and total-body photography is helpful for early recognition of melanoma in such cases (42). An unusual case of primary skin leiomyosarcoma was reported in 2018 in regards to a patient with TP53 mutation (loss of heterozygosity) presenting with LFS (43).

A retrospective Dutch study based on national registry data included 71 patients diagnosed with different skin cancers from 33 families with LFS; $59 \%$ of the subjects with skin cancers and LFS were females; the cumulative risk of skin cancers of these patients depending on age was $10.4 \%$ at 40 years, $25.2 \%$ at 60 years, and $44.6 \%$ at 70 years; the median age at diagnosis of the dermatological malignancies was 41 years, independent of other LFS-related cancers (44). In addition, by the age of 70 years, the cumulative risk for specific cancers was higher than the general population for the same geographic area: $12.6 \%$ for melanoma and $34.6 \%$ for basal cell carcinoma (44).

Another retrospective single center study on 89 subjects diagnosed between 2004 and 2015 with LFS showed a median age at first tumor diagnosis (regardless of the site and the type) of 25 years: $71 \%$ of individuals had primary multiple tumors and 2/89 patients had skin cancer, with a similar incidence for stomach, thyroid, lung carcinomas and leukemia in this mentioned cohort (45).

For the differential diagnosis of a patient with melanoma and tumors related to LFS including brain cancer, a case must be mentioned concerning melanoma-astrocytoma syndrome underlying $C D K N 2 A$ tumor-suppressor gene mutations (chromosome 9) (46).

On the other hand, non-syndromic mutations of the TP53 gene have been reported in many melanoma studies, as well as the immunohistochemistry expression of p53 which generally is associated with a poor prognosis (47). A genetic analysis of 154 patients with metastatic disease from different carcinomas, adenocarcinomas and melanomas identified TP53 out of 790 mutations as the most common driven pathway correlated with metastatic potential and drug resistance (48). A study of 38 subjects with desmoplastic melanoma showed a correlation between the depth of invasion and TP53 gene mutation $(\mathrm{P}=0.002)$ (49). The p53 protein is related to skin tumorigenesis, in terms of both melanoma and non-melanoma, and it may represent a future target of standard therapy (50). For instance, S-petasin is a molecule that activates the p53 pathway inducing anti-proliferative effects in melanoma cell lines (51).

\section{Future considerations}

Overall, LFS represents a very challenging condition for patients and physicians, as noted in other multiple endocrine and non-endocrine tumor combinations based on a common genetic background $(52,53)$. The timing of surgery, whether it includes adrenalectomy or melanoma removal, requires a multidisciplinary team of evaluation for improving the outcome but also the quality of life, not only the life span of the patients $(54,55)$. Whether or not hormonally active tumors such as adrenal neoplasia and related neuroendocrine anomalies promote the growth of MM, as suggested by some studies, is still a matter of discussion $(56,57)$. In addition, whether or not the phenotype of $\mathrm{MM}$ is more severe or atypical in relationship to the presence of other tumors and/or genetic anomalies is an open issue; on the one hand the patient has multiple associated tumors thus a more severe overall prognosis; but, on the other hand, since the patient has been diagnosed with a genetic condition, he/she may be re-assessed more frequently for serial check-ups $(58,59)$. Various biomarkers such as the E-cadherin family or TIMP proteins are suggested in order to be used as prognostic factors for MM $(60,61)$.

\section{Conclusions}

An important level of awareness involves skin cancer in LFS, particularly melanoma, despite the fact that it is not a part of 
the typical malignancy-containing picture. Patients with LFS seem to have a higher risk of developing MM when compared to the general population. The level of statistical evidence requires additional data to be conclusive. However, at least one dermatologic control is the first step in the multidisciplinary panel of surveillance of these patients; but in cases with benign and pre-malign pigmentations, serial dermatoscopy and full body photography are recommended for early melanoma detection in order to improve the prognosis and to reduce the overall malignancy burden.

\section{Acknowledgements}

Not applicable.

\section{Funding}

No funding was received.

\section{Availability of data and materials}

Not applicable.

\section{Authors' contributions}

FS drafted the manuscript and critically revised the final form. MCD is the corresponding author and revised the references. AP researched the literature, MC drafted the manuscript in light of the literature data, RCP researched the literature data, and AG approved the final form after review of the literature data. All the authors read and approved the final form of the manuscript for publication.

\section{Ethics approval and consent to participate}

Not applicable.

\section{Patient consent for publication}

Not applicable.

\section{Competing interests}

The authors declare they have no competing interests.

\section{References}

1. Frebourg T, Bajalica Lagercrantz S, Oliveira C, Magenheim R and Evans DG; European Reference Network GENTURIS: Guidelines for the Li-Fraumeni and heritable TP53-related cancer syndromes. Eur J Hum Genet 28: 1379-1386, 2020.

2. Miranda Alcalde B, Villa Alcázar M, Martínez Romera I and López Ibor B: The importance of Li-Fraumeni syndrome, a hereditary cancer predisposition disorder. Arch Argent Pediatr 119: e11-e17, 2021.

3. Fortuno C, Lee K, Olivier M, Pesaran T, Mai PL, de Andrade KC, Attardi LD, Crowley S, Evans DG, Feng BJ, et al: Specifications of the ACMG/AMP variant interpretation guidelines for germline TP53 variants. Hum Mutat 42: 223-236, 2021.

4. Wade KS, Estes JM and Kline RC: Genetics and the Gynecologic Patient. Ochsner J 20: 446-451, 2020.

5. Ueki A and Hirasawa A: Molecular features and clinical management of hereditary gynecological cancers. Int J Mol Sci 21: 9504, 2020 .
6. Mai PL, Best AF, Peters JA, DeCastro RM, Khincha PP, Loud JT, Bremer RC, Rosenberg PS and Savage SA: Risks of first and subsequent cancers among TP53 mutation carriers in the National Cancer Institute Li-Fraumeni syndrome cohort. Cancer 122: 3673-3681, 2016.

7. Monti P, Menichini P, Speciale A, Cutrona G, Fais F, Taiana E, Neri A, Bomben R, Gentile M, Gattei V, et al: Heterogeneity of TP53 Mutations and P53 Protein Residual Function in Cancer: Does It Matter? Front Oncol 10: 593383, 2020.

8. Zawacka-Pankau JE: The undervalued avenue to reinstate tumor suppressor functionality of the p53 protein family for improved cancer therapy-drug repurposing. Cancers (Basel) 12: 2717, 2020.

9. Levine AJ: p53: 800 million years of evolution and 40 years of discovery. Nat Rev Cancer 20: 471-480, 2020.

10. Fortuno C, Pesaran T, Mester J, Dolinsky J, Yussuf A, McGoldrick K, James PA and Spurdle AB: Genotype-phenotype correlations among TP53 carriers: Literature review and analysis of probands undergoing multi-gene panel testing and single-gene testing. Cancer Genet 248-249: 11-17, 2020.

11. Volc SM, Ramos CRN, Galvão HCR, Felicio PS, Coelho AS Berardineli GN, Campacci N, Sabato CDS, Abrahao-Machado LF, Santana IVV, et al: The Brazilian TP53 mutation (R337H) and sarcomas. PLoS One 15: e0227260, 2020.

12. Amadou A, Achatz MIW and Hainaut P: Revisiting tumor patterns and penetrance in germline TP53 mutation carriers: Temporal phases of Li-Fraumeni syndrome. Curr Opin Oncol 30: 23-29, 2018.

13. Consul N, Amini B, Ibarra-Rovira JJ, Blair KJ, Moseley TW, Taher A, Shah KB and Elsayes KM: Li-Fraumeni syndrome and Whole-body MRI screening: Screening guidelines, imaging features, and impact on patient management. AJR Am J Roentgenol 216: 252-263, 2021.

14. Grasparil AD II, Gottumukkala RV, Greer MC and Gee MS: Whole-body MRI surveillance of cancer predisposition syndromes: Current best practice guidelines for use, performance, and interpretation. AJR Am J Roentgenol 215: 1002-1011, 2020.

15. Iwasaki T, Mizumoto M, Numajiri H, Oshiro Y, Suzuki R, Moritani K, Eguchi M, Ishii E and Sakurai H: Re-irradiation using proton therapy for radiation-induced secondary cancer with Li-Fraumeni syndrome: A case report and review of literature. J Cancer Res Ther 16: 1524-1527, 2020.

16. Eulo V, Lesmana H, Doyle LA, Nichols KE and Hirbe AC: Secondary sarcomas: Biology, presentation, and clinical care. Am Soc Clin Oncol Educ Book 40: 1-12, 2020.

17. Pang LK, Pena M, Zhao R and Lee DF: Modeling of osteosarcoma with induced pluripotent stem cells. Stem Cell Res 49: 102006, 2020.

18. Czarnecka AM, Synoradzki K, Firlej W, Bartnik E, Sobczuk P, Fiedorowicz M, Grieb P and Rutkowski P: Molecular biology of osteosarcoma. Cancers (Basel) 12: 2130, 2020.

19. Schneider KW, Cost NG, Schultz KAP, Svihovec S and Suttman A: Germline predisposition to genitourinary rhabdomyosarcoma. Transl Androl Urol 9: 2430-2440, 2020.

20. Sandru F, Carsote M, Valea A, Albu SE, Petca RC and Dumitrascu MC: Somatostatinoma: Beyond neurofibromatosis type 1 (Review). Exp Ther Med 20: 3383-3388, 2020.

21. Evans DG, Woodward ER, Bajalica-Lagercrantz S, Oliveira C and Frebourg T: Germline TP53 testing in breast cancers: Why, when and how? Cancers (Basel) 12: 3762, 2020.

22. Le AN, Harton J, Desai H, Powers J, Zelley K, Bradbury AR, Nathanson KL, Shah PD, Doucette A, Freedman GM, et al: Frequency of radiation-induced malignancies post-adjuvant radiotherapy for breast cancer in patients with Li-Fraumeni syndrome. Breast Cancer Res Treat 181: 181-188, 2020.

23. Piombino C, Cortesi L, Lambertini M, Punie K, Grandi G and Toss A: Secondary prevention in hereditary breast and/or ovarian cancer syndromes other than BRCA. J Oncol 2020: 6384190, 2020.

24. Fortuno C, James PA and Spurdle AB: Current review of TP53 pathogenic germline variants in breast cancer patients outside Li-Fraumeni syndrome. Hum Mutat 39: 1764-1773, 2018.

25. Petry V, Bonadio RC, Cagnacci AQC, Senna LAL, Campos RDNG, Cotti GC, Hoff PM, Fragoso MCBV and Estevez-Diz MDP: Radiotherapy-induced malignancies in breast cancer patients with TP53 pathogenic germline variants (Li-Fraumeni syndrome). Fam Cancer 19: 47-53, 2020.

26. Orr BA, Clay MR, Pinto EM and Kesserwan C: An update on the central nervous system manifestations of Li-Fraumeni syndrome. Acta Neuropathol 139: 669-687, 2020.

27. Xiong Y, Zhang Y, Xiong S and Williams-Villalobo AE: A Glance of p53 functions in brain development, neural stem cells, and brain cancer. Biology (Basel) 9: 285, 2020. 
28. Valdez JM, Nichols KE and Kesserwan C: Li-Fraumeni syndrome: A paradigm for the understanding of hereditary cancer predisposition. Br J Haematol 176: 539-552, 2017.

29. Swaminathan M, Bannon SA, Routbort M, Naqvi K, Kadia TM, Takahashi K, Alvarado Y, Ravandi-Kashani F, Patel KP Champlin R, et al: Hematologic malignancies and Li-Fraumeni syndrome. Cold Spring Harb Mol Case Stud 5: a003210, 2019.

30. Jouinot A and Bertherat J: Diseases predisposing to adrenocortical malignancy ( $\mathrm{Li}$-Fraumeni syndrome, Beckwith-Wiedemann syndrome, and carney Complex). Exp Suppl 111: 149-169, 2019.

31. Petr EJ and Else T: Adrenocortical carcinoma (ACC): When and why should we consider germline testing? Presse Med 47: e119-e125, 2018

32. Carsote M, Ghemigian A, Terzea D, Gheorghisan-Galateanu AA and Valea A: Cystic adrenal lesions: Focus on pediatric population (a review). Clujul Med 90: 5-12, 2017.

33. Kamihara J, Rana HQ and Garber JE: Germline TP53 mutations and the changing landscape of Li-Fraumeni syndrome. Hum Mutat 35: 654-662, 2014

34. Baek YS, Seo JY, Song JY, Lee SY, Kim A and Jeon J: Li-Fraumeni syndrome presenting as cutaneous melanoma in a child: Case report and review of literature. J Eur Acad Dermato Venereol 33: e174-e175, 2019.

35. Akay BN, Okcu Heper A, Topcu V and Farabi B: A rare case of multiple cutaneous melanomas in Li-Fraumeni syndrome: A coincidental association or a component of the syndrome? Australas J Dermatol 60: e214-e216, 2019.

36. Curiel-Lewandrowski C, Speetzen LS, Cranmer L, Warneke JA and Loescher LJ: Multiple primary cutaneous melanomas in Li-Fraumeni syndrome. Arch Dermatol 147: 248-250, 2011.

37. Kollipara R, Cooley LD, Horii KA, Hetherington ML, Leboit PE, Singh V and Zwick DL: Spitzoid melanoma in a child with Li-Fraumeni syndrome. Pediatr Dev Pathol 17: 64-69, 2014.

38. Jacquemus J, Perron E, Pissaloux D, Alberti L and de la Fouchardière A: Atypical cutaneous melanocytic tumours arising in two patients with Li-Fraumeni syndrome. Pathology 49: 801-805, 2017.

39. Klein JD and Kupferman ME: Li-Fraumeni syndrome presenting as mucosal melanoma: Case report and treatment considerations Head Neck 39: E20-E22, 2017.

40. Hajkova N, Hojny J, Nemejcova K, Dundr P, Ulrych J, Jirsova K, Glezgova $\mathbf{J}$ and Ticha I: Germline mutation in the TP53 gene in uveal melanoma. Sci Rep 8: 7618, 2018.

41. Calvete O, Garcia-Pavia P, Domínguez F, Bougeard G, Kunze K, Braeuninger A, Teule A, Lasa A, Ramón Y Cajal T, et al: The wide spectrum of POT1 gene variants correlates with multiple cancer types. Eur J Hum Genet 25: 1278-1281, 2017.

42. Giavedoni P, Ririe M, Carrera C, Puig S and Malvehy J: Familial melanoma associated with Li-Fraumeni syndrome and atypical mole syndrome: Total-body digital photography, dermoscopy and confocal microscopy. Acta Derm Venereol 97: 720-723, 2017.

43. Sabater-Marco V, Ferrando-Roca F, Morera-Faet A García-García JA, Bosch SB and López-Guerrero JA: Primary cutaneous leiomyosarcoma arising in a patient With Li-Fraumeni Syndrome: A neoplasm with unusual histopathologic features and loss of heterozygosity at TP53 Gene. Am J Dermatopathol 40: 225-227, 2018

44. Nieuwenburg SA, Adan F, Ruijs MWG, Sonke GS, van Leerdam ME and Crijns MB: Cumulative risk of skin cancer in patients with Li-Fraumeni syndrome. Fam Cancer 19: 347-351, 2020.

45. Park KJ, Choi HJ, Suh SP, Ki CS and Kim JW: Germline TP53 mutation and clinical characteristics of Korean patients with Li-Fraumeni syndrome. Ann Lab Med 36: 463-468, 2016.
46. Chan AK, Han SJ, Choy W, Beleford D, Aghi MK, Berger MS, Shieh JT, Bollen AW, Perry A, Phillips JJ, et al: Familial melanoma-astrocytoma syndrome: Synchronous diffuse astrocytoma and pleomorphic xanthoastrocytoma in a patient with germline CDKN2A/B deletion and a significant family history. Clin Neuropathol 36: 213-221, 2017.

47. Hsieh CC and Shen CH: The potential of targeting P53 and HSP90 overcoming acquired MAPKi-resistant melanoma. Curr Treat Options Oncol 20: 22, 2019.

48. Pandey R, Johnson N, Cooke L, Johnson B, Chen Y, Pandey M, Chandler J and Mahadevan D: TP53 Mutations as a driver of metastasis signaling in advanced cancer patients. Cancers (Basel) 13: 597, 2021.

49. Alos L, Fuster C, Castillo P, Jares P, Garcia-Herrera A, Marginet M, Agreda F, Arance A, Gonzalvo E, Garcia M, et al: TP53 mutation and tumoral PD-L1 expression are associated with depth of invasion in desmoplastic melanomas. Ann Transl Med 8: 1218, 2020.

50. Loureiro JB, Abrantes M, Oliveira PA and Saraiva L: P53 in skin cancer: From a master player to a privileged target for prevention and therapy. Biochim Biophys Acta Rev Cancer 1874: 188438, 2020.

51. Guo L, Kang JS, Kang NJ and Choi YW: S-petasin induces apoptosis and inhibits cell migration through activation of p53 pathway signaling in melanoma B16F10 cells and A375 cells. Arch Biochem Biophys 692: 108519, 2020.

52. Carsote M, Valea A, Dumitru N, Terzea D, Petrova E, Albu S, Buruiana A and Ghemigian A: Metastases in daily endocrine practice. Arch Balkan Med Union 51: 478-482, 2016.

53. Baloescu R, Carsote M, Albu SE and Valea A: Multiple surgeries and long-term endocrine follow-up in a MEN2A syndrome. J Surgical Sciences 4: 1-4, 2015.

54. Paduraru DN, Nica A, Carsote M and Valea A: Adrenalectomy for Cushing's syndrome: Do's and don'ts._J Med Life 9: 334-341, 2016.

55. Poiana C, Carsote M, Chirita C, Terzea D, Paun S and Beuran M Giant adrenal cyst: Case study. J Med Life 3: 308-313, 2010

56. Caruntu C, Boda D, Constantin C, Caruntu A and Neagu M: Catecholamines increase in vitro proliferation of murine B16F10 melanoma cells. Acta Endocrinol 10: 545-558, 2014

57. Lupu M, Caruntu A, Caruntu C, Papagheorghe LML, Ilie MA, Voiculescu V, Boda D, Constantin C, Tanase C, Sifaki M, et al: Neuroendocrine factors: The missing link in non melanoma skin cancer. Oncol Rep 38: 1327-1340, 2017.

58. Grange JD, Duquesne N, Roubeyrol F, Branisteanu D, Sandon K, Fleury J, Gerard JP, Chauvel P, Pinzaru G, Jean-Louis B and Bievelez B: Double irradiation for macroscopic radioresistance or recurrence of melanomas of the posterior uvea: Clinical, ballistic, thera-peutic and prognostic aspects. Series of 19 cases among 462 patients. J Fr Ophtalmol 22: 1054-1063, 1999 (In French).

59. Ancuceanu R, Dinu M, Neaga I, Laszlo FG and Boda D: Development of QSAR machine learning-based models to forecast the effect of substances on malignant melanoma cells. Oncol Lett 17: 4188-4196, 2019.

60. Stefan O, Tudor G, Constantinescu C, Luca C, Boda D, Caruntu C, Cioplea M, Nichita L and Zurac SA: E-cadherin and N-cadherin expression pattern in common melanocytic nevi. Virchows Archiv 475 (Suppl): S28-S28, 2019.

61. Zurac S, Neagu M, Constantin C, Cioplea M, Nedelcu R, Bastian A, Popp C, Nichita L, Andrei R, Tebeica T, et al: Variations in the expression of TIMP1, TIMP2 and TIMP3 in cutaneous melanoma with regression and their possible function as prognostic predictors. Oncol Lett 11: 3354-3360, 2016. 